\title{
Comparing Pre-Paid Communal Water Metering and Delegated Management in Urban Poor Setting: Case Studies in Nakuru and Kisumu in Kenya
}

\author{
Robert Hanjahanja ${ }^{{ }^{*}}$, Christian Omuto², Elijah Biamah ${ }^{2}$ \\ ${ }^{1}$ Southern Region Water Board, Private Bag 72, Zomba, Malawi \\ ${ }^{2}$ Department of Environmental and Biosystems Engineering, University of Nairobi, Nairobi, Kenya \\ Email: ^roberthanja@yahoo.com, thineomuto@yahoo.com
}

How to cite this paper: Hanjahanja, R., Omuto, C., \& Biamah, E. (2018). Comparing Pre-Paid Communal Water Metering and Delegated Management in Urban Poor Setting: Case Studies in Nakuru and Kisumu in Kenya. Current Urban Studies, 6, 483-498. https://doi.org/10.4236/cus.2018.64026

Received: August 27, 2018

Accepted: November 16, 2018

Published: November 19, 2018

Copyright (c) 2018 by authors and Scientific Research Publishing Inc. This work is licensed under the Creative Commons Attribution International License (CC BY 4.0).

http://creativecommons.org/licenses/by/4.0/

cc) (i) Open Access

\begin{abstract}
Water service providers face multiple challenges in their service provision. These challenges include high non-revenue water, low water coverage, many incidences of waterborne diseases, and high water bills, etc. This study set to assess how changes in water metering strategies can overcome these challenges. The study analyzed three water metering technologies for their suitability to improve service provision. The strategies were: conventional water metering where meter-readers collect readings for post-billing; community prepaid metering (CPM) where meters are preloaded with tokens; and delegated meter management (DMM) where service provision and billing is delegated to master operators. CPM and DMM were installed in an existing conventional network and data on commonly-used performance evaluation parameters collected through interviews, field-visits, and existing literature. The results portrayed CPM and DMM with positive improvements to the conventional metering. CPM had over $70 \%$ improvements in unit cost of water and time for water access. DMM had over 90\% improvements in water coverage and non-revenue water. In general, the study found CPM with positive impacts on the cost of water, potable water, and time to fetching water while DMM had positive impacts on water coverage and non-revenue water. It's recommended that the CPM and DMM models used in this study be cross-tested and more individual strengths be drawn.
\end{abstract}

\section{Keywords}

Delegated Management Metering, Non-Revenue Water, Peri-Urban Water Supply, Pre-Paid Metering, Water Metering Management 


\section{Introduction}

Water service providers (WSP) often face many challenges in their service especially among the urban poor customers (Easterly, 2009). There is little focus on providing water to the urban poor resulting in low coverage, poor quality infrastructure, ineffective maintenance, illegal connections, vandalism which lead to high non-revenue water and services are unreliable, with frequent breakdowns and interruptions, and the facilities are poorly financed and do not always have strategies focused on the urban poor. Some of these challenges are management challenges that can be fixed by the WSPs. Chief among them is the non-revenue water which is reported to be as high as $50 \%$ in developing countries (Tremolet \& Hunt, 2016). Non-revenue water (NRW) is the difference between the volume of water supplied into a distribution network and the authorized billed consumption (Kamani et al., 2012). It's a financial loss to WSPs and also an avenue for degradation of water quality through the leakages and vandalized network. Technology with water metering is one of the reported ways to overcome some of the challenges in service provision (Tsitsifli et al., 2017). This study installed and tested two water metering technologies for their suitability to improve water service provision among urban poor communities.

Water metering is a management tool in water supply. It is used by the service providers to quantify water bill, for leak detection, monitoring water demand and plan for supply, among others (Maddaus, 2001). Many water metering technologies and models have been reported in the literature. Van Zyl described different types of water meters and where they are often used (Van Zyl, 2011). These meters also have some impacts on the type of water meter management in terms of meter reading and water billing. As such, there are meters that allow automatic reading and telemetric submissions to a central location and those that require a meter reader to periodically walk to the meter and collect the readings (Marais et al., 2016). There also those that are pre-loaded to allow water-use up to the loaded limit (Gambe, 2015). Flat rate billing is another approach that is often used in places with multiple metering problems (Bakker, 2001). Each of these water metering models has their own potentials and challenges especially when applied to informal settlements. For the challenges, there is a lot of literature on issues like non-revenue water, high cost of water per unit volume, frequent outages in water supply, low compliance to standards, among others (Chepyegon \& Kamiya, 2018).

In terms of water service provision, informal settlements are often considered problematic. This is because the areas are largely poorly planned without straight-lined roads and grids to lay the water pipes. In addition, there are often more occurrences of vandalism to water infrastructure and inordinate preference to illegal connections. The reality thought is that $72 \%$ of residents of urban cities in developing countries live in these communities, representing a population of up to 231 million people (Dovey \& King, 2012). These people have every right to access decent water services. 
There are varied reports in the literature where attempts have been made to improve water metering and water service provision to the urban poor. In South Africa, it was reported that Johannesburg Water implemented individual prepaid metering project in Phiri area (Dovey \& King, 2012). This new technology, while being very customer friendly, was resisted by the residents because they felt that there was an impingement on their right to access the $6 \mathrm{~m}^{3}$ free water as provided for in their constitution. As such, the individual prepaid metering project was unable to gain acceptability and ended abruptly. In Malawi, WaterAid in collaboration with Lilongwe Water Board tried the water-user-association approach with considerable success (Baietti et al., 2006). This approach basically mobilizes communities to manage a collection of metered communal water points while the water board developed a pro-poor unit that focuses on urban poor issues. Since the establishment of the water user associations, Lilongwe Water Board has been able to improve its revenue collection and understand the challenges in providing water to low income areas (Collignon \& Vezina, 2016). In Uganda, there was a pilot prepaid project, which involved individual connections. In this case, the water meter was considered too costly for low income consumers and the water service provider struggled to get customer acceptance (World Bank, 2016). In Kenya, the Water Kiosk model has been practiced. In this model, water points are metered and used to sell water directly to consumers who come to the water points. This water kiosk model has also been tried by Hawassa in Ethiopia (Njoroge, 2011). In other places where water service providers are unable to cope with the rapid growth in the peri urban areas, such as Maputo, private operators have mushroomed to fill the gap (Dovey \& King, 2012). These private operators ran their own metered water systems and account for over $60 \%$ of the municipal water supply. They are often unregulated especially in water tariff, coverage, and water quality (Mbuvi et al., 2012). In Morocco, the water service provider installed prepaid stand posts in the high density areas of Rabat, and these were well accepted by the residents: "This acceptance was reflected by the name given by users to the stand posts in the poetic Arabic language. After few weeks of use, it switched from Assaqaa, meaning "the stand post" to Saqayti, meaning "my stand post", says (Bakker, 2001). In Dar es Salaam, Tanzania, they introduced automated meters with a global positioning system (GPS) to efficiently observe its customers. The WSP was able to collect data and monitor each customer with the automated meter better, and provide a better service through timely and accurate billing, quicker tracing and repairing of leaks and better customer service (Gambe, 2015). The Municipality Corporation of Greater Mumbai, India, has in progress, a program where they were installing automated meters. Barely two years into the project, had the water service provider already registered major technical problems in repairs and picking up remote meter readings leading them to decide that In future, when innovating, they must be more conservative. Hypothetically, the automatic metering system is good but a pilot project and thorough due diligence should be con- 
ducted before the project is taken to scale (Mbuvi et al., 2012).

In Kenya, water supply is characterized by inadequate financing and unfocused, especially when serving the poor communities (Carter et al., 2011). For instance, most people are supplied with very scanty services with perhaps a standpipe or a communal water point which is also ill-maintained (WSTF, 2015). Although the water sector reform in the country since 2002 was partly focused to revolutionize and improve water service provision, there are still many cases of mismanagement and unqualified staff among water companies, under registration of meters, illegal water connections, frequent pipe bursts, old networks, and under billing in the water sector (WASREB, 2011). The poor and mostly the urban communities are the major victims of these poor water services (WSTF, 2015). In Nakuru and in Kisumu cities in Kenya, the problem is exemplified even more because the water utilities are struggling with low coverage (69\%) and very high non-revenue water (52\%) in the low income areas (Saria, 2015).

The focus of this study was to compare two water metering strategies in $\mathrm{Na}$ kuru and Kisumu and to examine how these tools can improve water service provision to the urban poor.

\section{Materials and Methods}

\subsection{Study Area}

This study was carried out in Nakuru and Kisumu in Kenya (Figure 1). Kisumu is the third largest city in Kenya while Nakuru is the fourth largest city. By the end of the year 2017, the projected population was 800,000 in Kisumu and 760,000 in Nakuru. About $80 \%$ of Nakuru and Kisumu populations live below the global poverty line and are largely concentrated in the densely populated peri-urban areas (UN-DESA, 2017).

In terms of water supply, $70 \%$ of the population in Nakuru is served by the Nakuru Water and Sanitation Services Company (NAWASSCO) with over 40,900 metered connections (WASREB, 2011). In Kisumu, WASREB reported that $29 \%$ of the population is provided with water by Kisumu Water and Sewerage Corporation (KIWASCO) with over 14,000 metered connections (WASREB, 2011) (Table 1).

Table 1. General water provision information in the study areas (WASREB, 2011).

\begin{tabular}{ccc}
\hline Parameter & Nakuru Town & Kisumu Town \\
\hline Total population in service area & 674,789 & 525,313 \\
Population served & 472,352 & 153,083 \\
Percentage of population served & $70.0 \%$ & $29.1 \%$ \\
Number of metered connections & 40,910 & 14,084 \\
Non-Revenue Water (NRW) & $47 \%$ & $80.2 \%$ \\
Drinking water quality compliance (KEBS \& WHO standards) & $64 \%$ & $91 \%$ \\
Average time to fetch water from nearest water point & 1 hour & 1 hour \\
\hline
\end{tabular}

KEBS: Kenya Bureau of Standards; WHO: World Health Organization. 


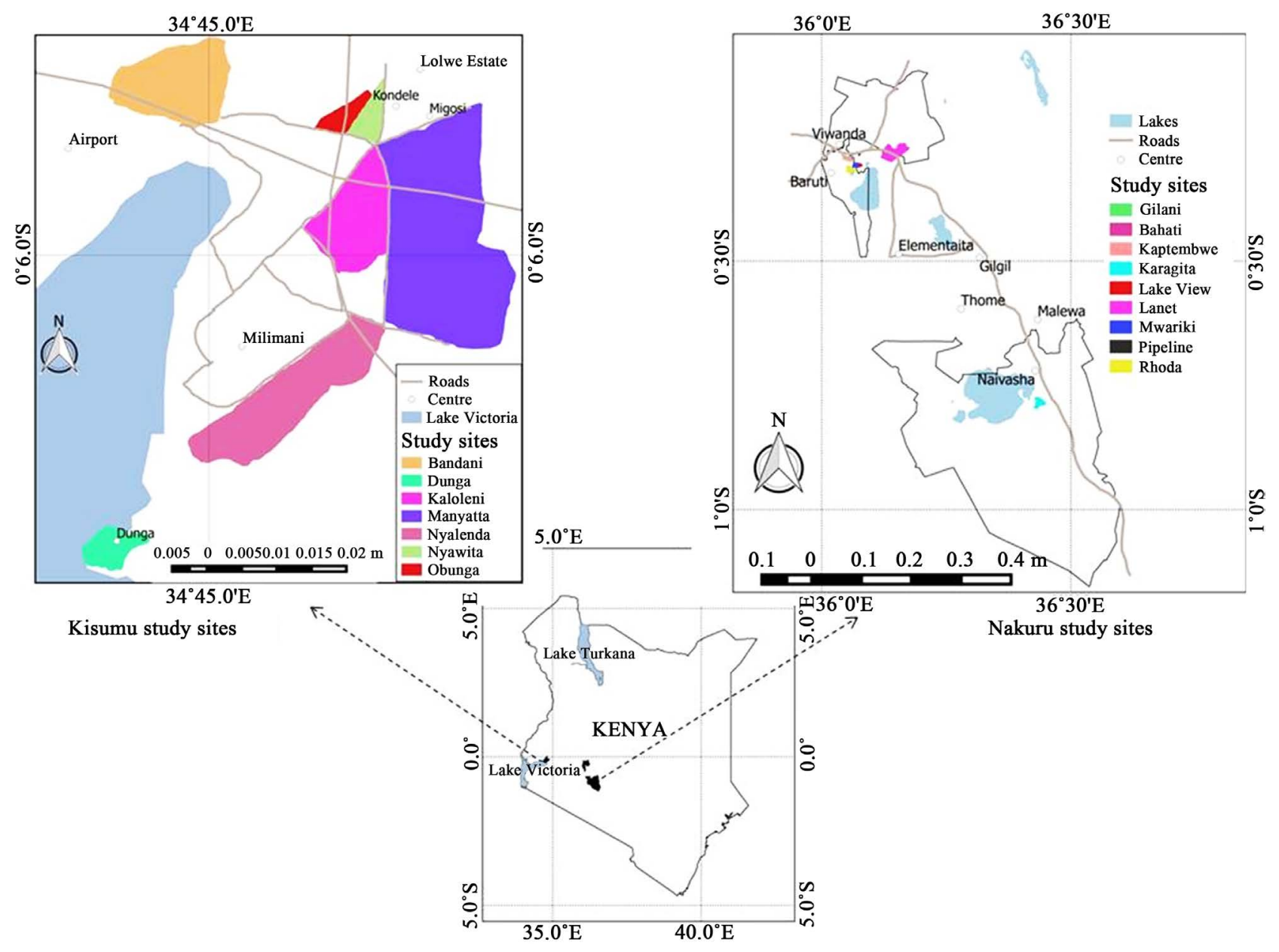

Figure 1. Location of study areas.

\subsection{Water Metering Models}

Two water metering models were installed and tested in the study area: communal prepaid metering and delegated management metering (Figure 2). The communal prepaid metering (CPM) was installed in Nakuru. In this model, water meters are activated using tokens that are bought from the water service provider. The tokens are uploaded with credit at designated pay-points and water users can draw water up to the amount credited in the token. The delegated management metering (DMM) was installed in Kisumu. Here, a master meter is used to monitor water entering a given area which is also known as delegated area. Every delegated area is managed by a master operator who is responsible for the water bill into that area and for the operation and network maintenance in the area. The master operator in turn bills water users in this area.

There were 91 communal prepaid meters installed in the network in Nakuru and 6 master meters for the DMM installed in the network in Kisumu between January 2011 and January 2012. The development and installation of the water meters were carried out in accordance with the Government of Kenya guidelines (WASPA, 2018). The prepaid meters were installed to improve the quality of 


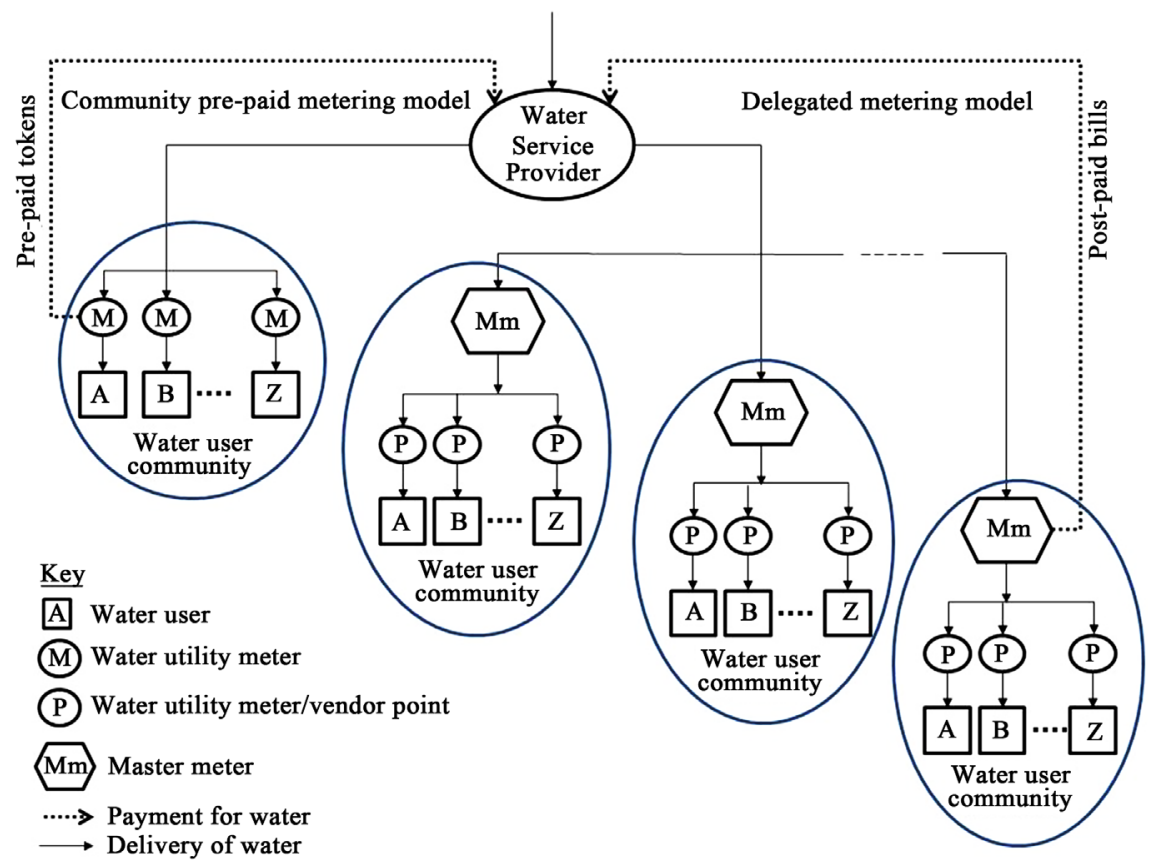

Figure 2. Conceptual water metering models.

water service delivery to 15,000 people in the six low-income settlements in $\mathrm{Na}$ kuru (Figure 1). In Kisumu, one master meter was installed in each of the six slum areas (Figure 1). The DMM model targeted 1539 individual connections and 1557 metered connections serving schools, medical facilities, and water kiosks.

\subsection{Data Collection}

This study was designed such that the two study sites in Nakuru and Kisumu cities were each divided into two: areas with and areas without the study metering models but which are served by the same water service provider (WSP). The areas without the study metering models had the old conventional metering models installed by the WSP. The old conventional model consists of a distribution network with mechanical meters at the consumer premises and from which meter-readers collect the readings at the end of every month for billing water consumed.

During this study, equal number of samples was randomly selected from the two groups (with and without study metering models) in each study site. Data was collected through field visits, interviews, and focused group discussions. Interviews targeted water-user households, water vendors/meter operators, and staff members of the WSPs. Focused group discussions were done with members of water user associations, association of WSPs, association of water vendors, and association of landlords.

Data collection was carried out during the first dry seasons of the year between January and March 2012 and repeated during the second dry season be- 
tween July and September 2012. This was first hand data collected during this specific time because is when this study was conducted. Having implemented the DMM and the CPM, it was important to collect data at the time, to be able to determine what immediate impact the interventions had during implementation and post the fact for the two respective communities. Dry seasons were selected because these are the times for high household water demand in the study area and in the country in general (WASREB, 2011). Data was collected on the following parameters: potable water, non-revenue water, the cost of water, water coverage, access, time for fetching water from the nearest water point, and incidence of water-borne diseases. These parameters are also often used in performance evaluation of WSPs in Kenya (WASREB, 2011).

The samples for interviews included 532 households (243 in Nakuru and 288 in Kisumu) and 133 employees of the WSPs (84 in NAWASSCO and 49 in KIWASCO). These samples were uniformly allocated throughout the target slum areas ( 9 in Nakuru and 6 in Kisumu). The interviews were administered using predesigned questionnaires. The questionnaires were designed to respond to the question asked, i.e. what are the essential functions required of communal prepaid meters and the delegated management model to heighten the delivery of water in Kenyan high density areas. Open-ended questionnaires were given out while conducting both unstructured and structured interviews. In order to have an ease of process when analyzing the findings, it was opted to use both ordinal and nominal data. Nominal variables were used for marking values such as the geographic growth of the two Kenyan towns and ordinal scales to provide information about the choices available to the targeted customers. The data collection methodology therefore was through primary means by surveys through the questionnaires and also other means like key informant interviews, observation and focus group discussions. The questionnaires for household/water-vendor interviews targeted the following parameters: the time taken when fetching water, experience of incidences of waterborne diseases, and cost of water from the WSP. The questionnaires for interviews with WSPs focused on potable water, water coverage, and non-revenue water. Field visits targeted the frequency of outages in water supply and leakages in the distribution network. All together there were 14 field visits during the study ( 7 in Nakuru and 7 in Kisumu). Focused group discussions (FGD) targeted overall community views on the study parameters with regard to water service provision. There were 10 FGDs: 6 in Nakuru and 4 in Kisumu.

\subsection{Data Analysis}

Comparative statistical analysis of the study parameters was done between cases with and without installed study metering models. One-way analysis of variance (ANOVA) was used to compare the means for each study parameter in an attempt to determine the impact of the CPM and DMM in the study areas. Analysis was done at $5 \%$ level of significance. 


\section{Results}

\subsection{Perspectives of Water Users}

Household interviews with water users established that the cost of water was erratic and relatively high in areas that did not have the study water metering models (Figure 3). On average and in areas without the study metering model, the water users felt that 20-liter of water cost more than Kenya Shilling (KES) 10. In the areas with installed water metering, the cost of water was fixed at KES 1.2 for 20 liters. FGD identified the main reasons for high cost of water as malfunctioning meters, inaccurate meter readings, and frequent outages that forced water users to seek the services of illegal and often expensive water vendors. In terms of incidences of waterborne diseases, the majority of water users in Kisumu where the study metering models were not installed felt that there had been very many incidences of the diseases in the area. In Nakuru, the corresponding

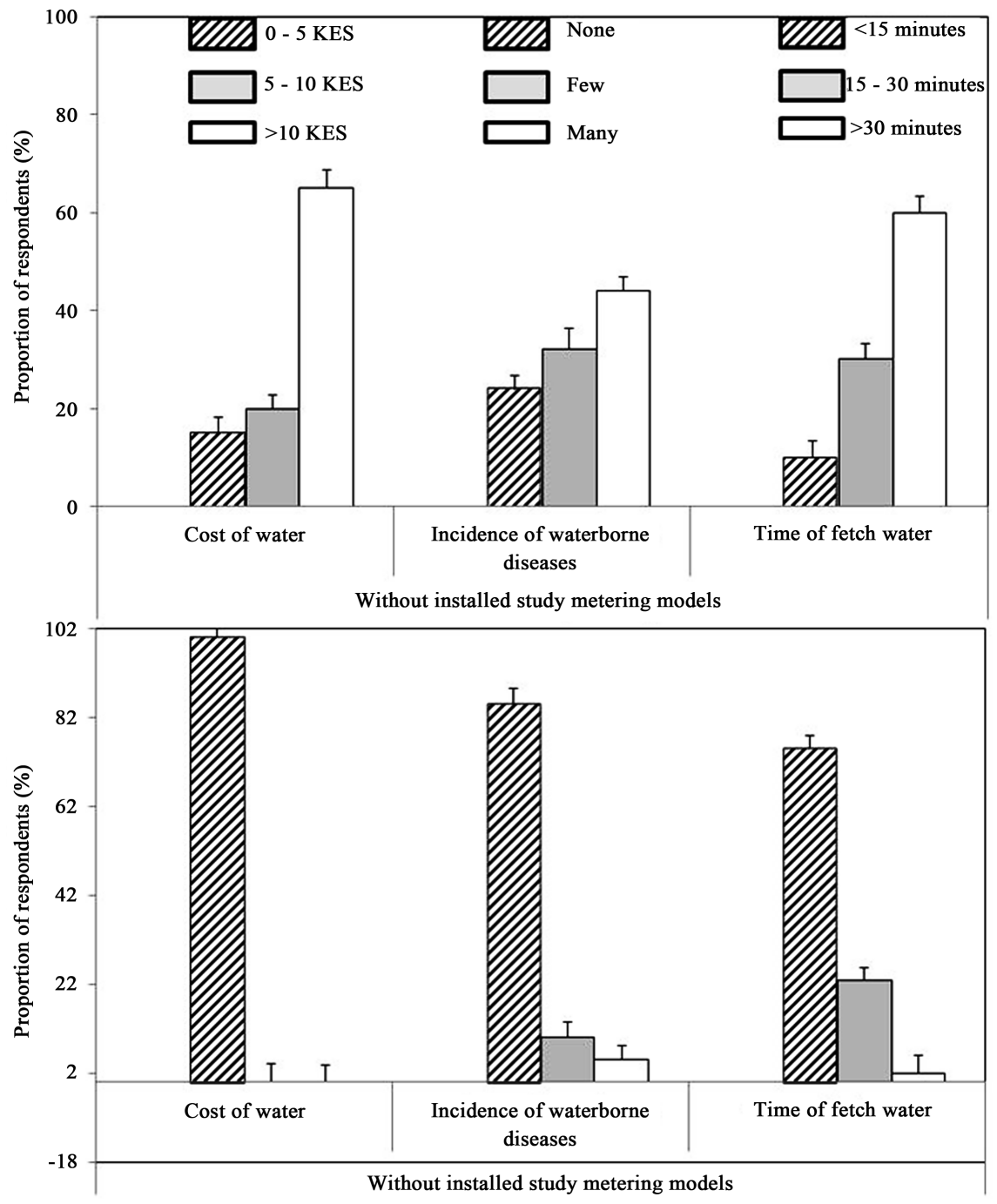

Figure 3. Summary responses from household interviews on water service provision (whiskers are st.dev). 
group felt that the incidences had been few (Figure 3). Nonetheless, these incidences were more than those from the areas in which the study models had been installed. FGD identified frequent use of the contaminated lake water as the main driver to the many incidences of waterborne diseases in Kisumu. This was further explained that the majority of Kisumu residents resort to the lake water whenever they could not access piped water. The group discussion results also suggested that the lake water is freely available compared to the highly priced utility water.

In areas with old metering models, water users seemed to spend more time to fetch water. This study found that more than $80 \%$ of water users in these areas spend more than 30 minutes to fetch water. The main reasons for the time spent to fetch water included long queues at the watering points, relatively long distance to the nearest cheap alternative source of water, and frequent outages at the nearest water point. In comparison, more than $75 \%$ of water users in areas where the study metering models were installed spent less than 15 minutes in fetching water (Figure 3). This was because water was always available at the water points and that there were many well-managed water points in each area.

\subsection{Perspectives of Water Service Providers}

Non-revenue water (NRW) at $76 \%-78 \%$ was higher in Kisumu than in Nakuru at $45 \%-49 \%$ (Table 2). This collates directly with the number of water outages ( $84 \%$, Kisumu and 61\%, Nakuru) and incidents of leakage (79\%, Kisumu and $75 \%$, Nakuru). Further assessment showed that Nakuru Water and Sanitation Services Company Limited (NAWASCO) had more supervisory visits per month for their water supply network than Kisumu Water and Sewerage Company Limited (KIWASCO), hence the lower figures for the critical performance indicators. In addition, the water users in Nakuru seemed to have limited alternative sources of water compared to Kisumu and consequently tend to secure their water points. All these factors could have contributed to low NRW than in Kisumu. NRW was also considerably low in areas where the study metering models were installed (Table 2). The study metering models appeared to engage the water

Table 2. Summary performance indicators from water service providers.

\begin{tabular}{ccccc}
\hline & \multicolumn{2}{c}{ Nakuru study area } & Kisumu study area \\
\cline { 2 - 4 } & $\begin{array}{c}\text { With study } \\
\text { models }\end{array}$ & $\begin{array}{c}\text { Without study } \\
\text { models }\end{array}$ & $\begin{array}{c}\text { With study } \\
\text { models }\end{array}$ & $\begin{array}{c}\text { Without study } \\
\text { models }\end{array}$ \\
Non-revenue water & $14 \%$ & $45 \%-49 \%$ & $6 \%$ & $76 \%-88 \%$ \\
Proportion of water outage & $11 \%( \pm 2.1)$ & $61 \%( \pm 3.3)$ & $9 \%( \pm 0.3)$ & $84 \%( \pm 4.1)$ \\
Incidences of network leakage & $17 \%( \pm 1.1)$ & $75 \%( \pm 2.4)$ & $12 \%( \pm 0.9)$ & $79 \%( \pm 2.6)$ \\
Compliance with KEBS standards & $98 \%$ & $95 \%$ & $98 \%$ & $92 \%$ \\
Compliance with WHO standards & $100 \%$ & No records & $98 \%$ & No records \\
\hline
\end{tabular}


users into proactivity in water management. This was achieved through prepayment in Nakuru and through master operators in Kisumu. It's important to note that the master operators are also members of the water user community. Consequently, the new metering models were able to infuse some sense of responsibility and care for water which eventually kept cases of vandalism and water theft under check. As a result, the key performance indicator for both Kisumu and Nakuru dropped to $6 \%$ and $14 \%$ respectively. Other indicators such as the proportion of water outages and the incidences of water leaking also dropped to $12 \%$ and $17 \%$ for Kisumu and Nakuru. In terms of compliance to KEBS and WHO, both water service providers were not impacted significantly as both were already operating in compliance with the laid out standards.

During the field visits, many incidences of water supply outages were found in areas without the installed metering models compared to those that had the installed models. The outages were more in Kisumu than in Nakuru. In addition, Kisumu also had indications of many cases of pipe leakages in the network. These results suggested the potential for lower water coverage in Kisumu than in Nakuru for the areas that did not have installed study metering models. The impression was that Kisumu posed more water provision challenges than in Nakuru. For the areas with installed metering models, the study found the incidences of water supply outage and leakages well below 20\% (Table 2). Again, these results reinforce the notion that the water users could play important roles in water supply management if management tools can incorporate their participation.

\subsection{Performance Evaluation of Water Service Providers}

Mean non-revenue water (\%) was higher in areas without the study metering models than in areas where the metering models were installed (Table 3 ).

Table 3. Summary mean performance parameters for water service provision.

\begin{tabular}{|c|c|c|c|c|}
\hline \multirow[b]{2}{*}{$\begin{array}{l}\text { Performance } \\
\text { parameter }\end{array}$} & \multicolumn{2}{|c|}{ Nakuru study area } & \multicolumn{2}{|c|}{ Kisumu study area } \\
\hline & Without CPM & With CPM & Without DMM & With DMM \\
\hline $\begin{array}{c}\text { Non-revenue } \\
\text { water }\end{array}$ & $47 \%$ & $14 \%$ & $80 \%$ & $6 \%$ \\
\hline Cost of Water & $\begin{array}{c}\text { KES } 6.3 \text { (USD 0.08) } \\
\text { per } 20 \text { liters }\end{array}$ & $\begin{array}{l}\text { KES } 1.2 \text { (USD } 0.01 \\
\text { per } 20 \text { liters }\end{array}$ & $\begin{array}{l}\text { KES } 823 \text { (USD 10) } \\
\text { per month }\end{array}$ & $\begin{array}{c}\text { KES } 500 \text { (USD 6.10) } \\
\text { per month }\end{array}$ \\
\hline $\begin{array}{c}\text { Incidence of } \\
\text { waterborne } \\
\text { diseases }\end{array}$ & $\begin{array}{l}\text { 21\% compliance } \\
\text { (KEBS standards) }\end{array}$ & $\begin{array}{l}\text { 91\% compliance } \\
\text { (KEBS standards) }\end{array}$ & $\begin{array}{l}\text { 19\% compliance } \\
\text { (KEBS standards) }\end{array}$ & $\begin{array}{l}\text { 90\% compliance } \\
\text { (KEBS standards) }\end{array}$ \\
\hline $\begin{array}{l}\text { Time for } \\
\text { fetching water }\end{array}$ & 1 hour & 15 minutes & 1 hour & 30 minutes \\
\hline Potable water & $\begin{array}{l}\text { 95\% compliance } \\
\text { (KEBS standards) }\end{array}$ & $\begin{array}{l}\text { 100\% compliance } \\
\quad \text { (KEBS and } \\
\text { WHO standards) }\end{array}$ & $\begin{array}{l}\text { 92\% compliance } \\
\text { (KEBS standards) }\end{array}$ & $\begin{array}{c}\text { 98\% compliance } \\
\text { (KEBS and WHO } \\
\text { standards) }\end{array}$ \\
\hline Coverage & $79 \%$ & $92 \%$ & $48 \%$ & $93 \%$ \\
\hline
\end{tabular}


Non-revenue water (NRW) is the amount of water produced for which revenue is not received (Liemberger \& Wyatt, 2018). NRW is usually caused by factors such as water losses from leaky pipes, malfunctioning meters that charge too little, vandalism of water distribution network, or due to illegal connections to the water network. In Kisumu, NRW was highest for areas without the study metering models; giving the impression that the area had most challenges with water supply. It's interesting to note that the same areas in Kisumu also had the lowest indicator of water coverage (Table 3). Water coverage is the proportion of a population that has been served with potable water for more than 20 hours a day. $75 \%$ coverage in an area is generally considered to be an indication of high performance (Collignon \& Vezina, 2016). In this study, the areas without the study metering models in Kisumu had the lowest water coverage (Table 3). Both CPM and DMM surpassed the $75 \%$ water coverage mark and could be considered to have had high performance in terms of water coverage.

In Nakuru, CPM areas had NRW which was $70 \%$ lower than in areas without CPM and 80\% lower in cost of water per 20 litres than in areas without CPM. These comparative results suggest better management of water supply in the areas with installed CPM. Since the water users improved their stake in the water supply management through prepayment, they more or less shared the management responsibilities by protecting the distribution network. Perhaps this also contributed to the low NRW and eventual improved network management in the CPM model. Furthermore, the water distribution network seemed better than areas without CPM going by the reduced time for fetching water by $75 \%$ (Table 3). Overall, the low NRW and time for fetching water in CPM areas gave the impression of improved coverage and efficiency in water supply.

In Kisumu, NRW was lower in areas with installed DMM than areas without by over $92 \%$. The time for fetching water was also reduced by half compared to the areas without DMM (Table 3). The combined effect of time for fetching water and NRW could have contributed to increased water coverage by more than 90\%. Like in Nakuru, it's possible that the DMM contributed to improved efficiency in water service provision and shared management responsibilities with water users in terms of water supply and maintenance of the distribution network.

Analysis of variation between the cases with- and without-installed metering models at 5\% level of significance showed that CPM and DMM had significant positive difference on the water service provision performance parameters when compared to areas that did not have the metering models. It was also established that the DMM had more positive impacts on water coverage, incidences of no waterborne diseases and non-revenue water. The CPM model seemed to have had more positive impacts on cost of water, potable water and time for fetching water from the nearest water point (Figure 4).

\section{Discussion}

The results from this study showed that although metering of water can 


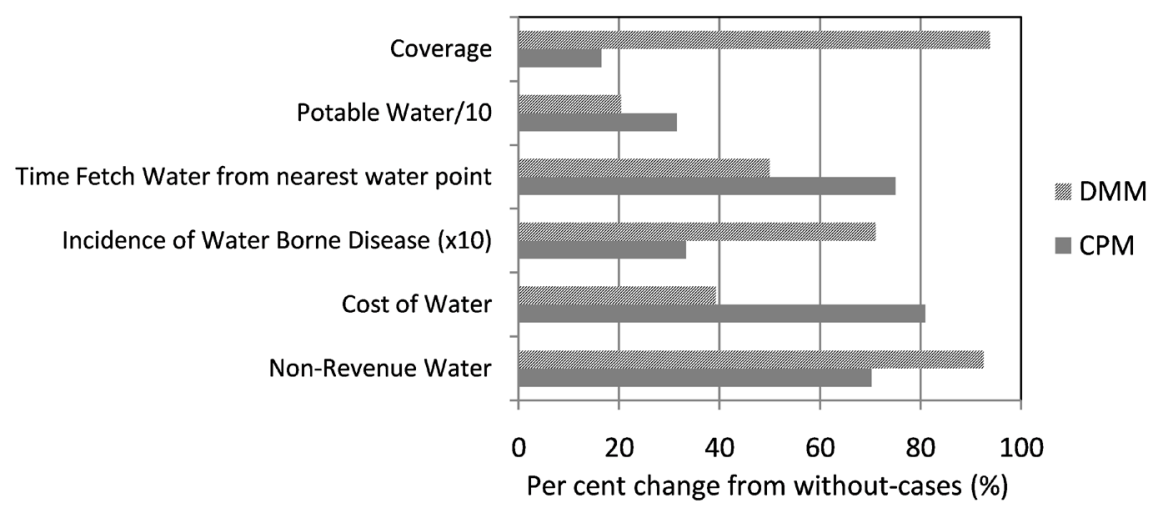

Figure 4. Comparison of impacts of CPM and DMM metering models.

potentially improve management of water service provision, much improvement can be realized if ingenuity is included in the management of the metering. Water meters enforce a sense of water use efficiency on the part of consumers because the water user must settle their water bills. Water meters also help water service providers to quantify the amount of supplied water to the consumer, which is eventually useful in planning water budgets (Alegre, 1999). However, the water meter alone is not enough in managing water provision. Water users need to be content that the bills from the water meter readings truly represents the actual water used. Prepaid water metering is one way of building trust with the water users on water billing. The water users not only ensure commensurate water bill with consumption, they are also ingeniously incorporated in the water management through their active involvement in monitoring the water use and billing (Heymans et al., 2014). In this study, the CPM model came out as a viable tool for managing the cost of water (Figure 3). Although there have been discussions for and against the use of prepaid meters in the literature (von Schnitzler, 2008) the management of prepaid meters seem to have some positive impacts on water cost and water-user trustworthiness of the water bills.

One of the goals of WSPs as business entities is to attain adequate customer satisfaction. This can be assessed through reduced incidences of waterborne diseases, sufficient water coverage in demand localities, and reduced time for getting water access (Gallego-Ayala et al., 2014; Haider et al., 2014). Comparing the performance of the DMM and CPM with cases of conventional metering, this study has demonstrated remarkable improvements in water coverage, reduced incidences of waterborne diseases, and reduced time for fetching water (Table 3). The DMM, which is a new concept in water metering, portrays a better approach for increasing water coverage and reduced incidences of waterborne diseases. The model penetrates the water users through a sub-business model that integrates the representation of the water-user community in water service provision and billing. As long as there is latitude for business profit and quality (or monitored) service provision, opportunities for growth are wide which eventually serve to increase the water coverage. This study showed how the water coverage grew by more than twofold through use of only six master operators in 
a municipality (Figure 3).

Non-revenue water in water supply is caused by a number of contributors. They include unmetered consumption, inaccuracies in registration of water meters, illegal consumption, and water tariffs, among others (Liemberger \& Wyatt, 2018). These are brought about by vandalism, illegal connections, poor meter management, or lack of metering. Vandalism/and or physical loss of supply network also occasion intermittent water supply and water rationing especially during network shutdown for repair works. There could be chances of contamination entering the network during shutdown or through leakages. The endeavor of WSPs is to minimize non-revenue water in order to make profit. Lowering NRW also has the potential of increasing water quality since the avenues of contamination are reduced (WASPA, 2018). In this study, the inverse relationship between NRW and incidences of waterborne diseases was also observed (Table 3). The DMM, which has more water-user engagement in network management through master operators, had the highest improvement in lowering NRW (Figure 3). This shows that the network management factors driving NRW can be partially addressed using a proactive metering management.

\section{Conclusion}

This study analyzed three water metering strategies: the conventional water metering where meter readers visit the meters once a month to collect the readings for post-billing; community prepaid water metering (CPM) in which water meters are preloaded with tokens that are used up to the loaded amount; and delegated metering (DMM) in which service provision and billing is delegated to master operators in a given area. The conventional metering was portrayed with many service provision challenges, such as high non-revenue water (NRW), low water coverage, many incidences of waterborne diseases, and high and erratic water bills. In effect, it does not serve the water users and water service providers well. Both CPM and DMM were portrayed with positive improvements in water provision focusing on the water users and water service providers. The CPM had positive impacts on the cost of water, potable water, and time to fetching water from the nearest water point. The DMM had positive impacts on water coverage, incidences of no waterborne diseases and non-revenue water. These are the key challenges that water service providers encounter when serving the urban poor, and the CPM and DMM are providing service providers with practical ways in addressing them.

There was no opportunity to test the CPM in Kisumu and the DMM in Nakuru, and this is the deficiency in the study. It's recommended that the CPM and DMM models used in this study be cross-tested and more individual strengths be drawn. Since the study was limited to the Kenyan experience, they can also be widely tested in situations where the main water provision challenges are similar to those that are portrayed in this study as model strong points, but in other countries within the region or indeed in the wider third world. 


\section{Acknowledgements}

The success of the study was made possible through financial support that came from the program, USAID-SUWASA, and time and expertise of the following people: Dr. Dennis Mwanza, Mr. Eric Adams, Mr. Nick Wahome, and Dr. Wisdom Changadeya. Special gratitude goes to the staff of NAWASCO and KIWASCO, KAWSAP and community members from Nakuru and Kisumu who took part during this study.

\section{Author Contributions}

This research article had three authors, and their individual contributions are described as follows: "Conceptualization, Robert Hanjahanja and Christian Omuto; Methodology, Robert Hanjahanja; Software, Christian Omuto; Validation, Christian Omuto, and Elijah Biamah; Formal Analysis, Robert Hanjahanja; Investigation, Robert Hanjahanja; Resources, Robert Hanjahanja; Data Curating, Christian Omuto; Writing-Original Draft Preparation, Robert Hanjahanja; Writing-Review \& Editing, Christian Omuto; Visualization, Christian Omuto; Supervision, Christian Omuto \& Elijah Biamah; Project Administration, Robert Hanjahanja; Funding Acquisition, Robert Hanjahanja”.

\section{Funding}

This research was funded by USAID-SUWASA under Contract No. AID-EPP-I-04-04-00019, Task Order No. 4, which was USAID's first significant urban water and sanitation reform effort in Africa on a regional basis. SUWASA's achievements were based, in part, on employing and working through African experts with a rich understanding of the challenges and culture of the continent.

\section{Conflicts of Interest}

The authors declare no conflicts of interest regarding the publication of this paper.

\section{References}

Alegre, H. (1999). Performance Indicators for Water Supply Systems. In E. Cabrera, \& J. García-Serra (Eds.), Drought Management Planning in Water Supply Systems (p. 32). Dordrecht: Water Science and Technology Library, Springer. https://doi.org/10.1007/978-94-017-1297-2_7

Baietti, A., Kingdom, W., \& Ginneken, M. V. (2006). Characteristics of Well Performing Public Water Utilities (pp. 8-16). Washington DC: Water Supply and Sanitation Working Notes, World Bank.

Bakker, K. (2001). Paying for Water: Water Pricing and Equity in England and Wales. Transactions of the Institute of British Geographers, 26, 143-164. https://doi.org/10.1111/1475-5661.00012

Carter, R., Casey, V., \& Harvey, E. (2011). WATERAID Sustainability Framework (pp. 
88-104). London, UK: Water Aid.

Chepyegon, C., \& Kamiya, D. (2018). Challenges Faced by the Kenya Water Sector Management in Improving Water Supply Coverage. Journal of Water Resource and Protection, 10, 85-105. https://doi.org/10.4236/jwarp.2018.101006

Collignon, B., \& Vezina, M. (2016). Independent Water and Sanitation Providers in African cities. Upper Hill, Nairobi: Water and Sanitation Programme, World Bank.

Dovey, K., \& King, R. (2012). Informal Urbanism and the Taste for Slums. Tourism Geographies, 14, 37-41. https://doi.org/10.1080/14616688.2011.613944

Easterly, W. (2009). How the Millennium Development Goals Are Unfair to Africa. World Development, 37, 26-35. https://doi.org/10.1016/j.worlddev.2008.02.009

Gallego-Ayala, J., dos Santos Dimene, C., Munhequete, A., \& Amos, R. (2014). Assessing the Performance of Urban Water Utilities in Mozambique Using a Water Utility Performance Index. Water $S A$, 40, 665-675. https://doi.org/10.4314/wsa.v40i4.12

Gambe, T. R. (2015). Prospects of Prepaid Smart Water Metering in Harare, Zimbabwe. African Journal of Science, Technology, Innovation and Development, 7, 236-246.

Haider, H., Sadiq, R., \& Tesfamariam, S. (2014). Performance Indicators for Small- and Medium-Sized Water Supply Systems: A Review. Environmental Reviews, 22, 1-40. https://doi.org/10.1139/er-2013-0013

Heymans, C., Eales, K., \& Franceys, R. (2014). The Limits and Possibilities of Prepaid Meters in Urban Africa: Lessons from the Field. Washington DC: World Bank.

Kamani, H., Malakootian, M., Hoseini, M., \& Jaafari, J. (2012). Management of Non-Revenue Water in Distribution Network and Conveyor Lines: A Case Study. Health Scope, 1, 147-152. https://doi.org/10.5812/jhs.7631

Liemberger, R., \& Wyatt, A. (2018). Quantifying the Global Non-Revenue Water Problem. Water Science and Technology: Water Supply-AQUA.

Maddaus, L. (2001). Effects of Metering on Residential Water Demand for Davis. Sacramento, CA: Brown and Caldwell.

Marais, J., Malekian, R., Ye, N., \& Wang, R. (2016). A Review of the Topologies Used in Smart Water Meter Networks: A Wireless Sensor Network Application. Journal of Sensors, 2016, Article ID: 9857568. https://doi.org/10.1155/2016/9857568

Mbuvi, D., De Witte, K., \& Perelman, S. (2012). Urban Water Sector Performance in Africa: A Step-Wise Bias-Corrected Efficiency and Effectiveness Analysis. Utilities Policy, 22, 31-40. https://doi.org/10.1016/j.jup.2012.02.004

Njoroge, M. (2011). The Billion Dollar Master Plan to Address Cities Water Woes (pp. 28-30). Nairobi: Athi Water Services Board.

Saria, J. A. (2015). Effects of Water Pipe Leaks on Water Quality and on Non-Revenue Water: Case of Arusha Municipality. Journal of Water Resources and Ocean Science, 4, 86-91.

Tremolet, S., \& Hunt, C. (2016). Taking Account of the Poor in Water Sector Regulation. Water Supply and Sanitation Working Note No. 11, Washington DC: World Bank.

Tsitsifli, S., Kanakoudis, V., Kouziakis, C., Demetriou, G., \& Lappos, S. (2017). Reducing Non-Revenue Water in Urban Water Distribution Networks Using DSS Tools. Water Utility Journal, 16, 25-37.

UN-DESA (2017). Urban Population, Development and the Environment. New York: United Nations.

Van Zyl, J. E. (2011). Introduction to Integrated Water Meter Management (pp. 25-49). Johannesburg: Water Research Commission. 
von Schnitzler, A. (2008). Citizenship Prepaid: Water, Calculability, and Techno-Politics in South Africa. Journal of Southern African Studies, 34, 899-917.

https://doi.org/10.1080/03057070802456821

WASPA (2018). Technical Guidelines for Water Meter (Management) in Kenya. Nairobi: WASPA.

http://waspakenya.or.ke/water-services-providers-association-waspa-technical-guidelin e-for-water-meter-management-kenya-June-2015.pdf

WASREB (2011). A Performance Report of Kenya's Water Services Sub-Sector (Issue 4), Real One Concepts. Nairobi.

Water Services Trust Fund WSTF (2015). Sustainable up Scaling of Access to Water for the Urban Poor, Survey on the Impact of Formalised Water Kiosks on Living Conditions in Athi River \& Ongata Rongai. Nairobi: WSTF.

World Bank (2016). Evaluation of Delegated Management Model Implemented in Kisumu Water and Sewerage Company (KIWASCO) Kisumu, Kenya, WSP, Upper Hill. Nairobi. 